\title{
Randomized, controlled clinical trial on the efficacy of nonsteroidal antiinflammatory drugs for the treatment of acute puerperal metritis in dairy cows
}

\author{
A. Pohl, S. Bertulat, S. Borchardt, O. Burfeind, and W. Heuwieser ${ }^{1}$ \\ Clinic of Animal Reproduction, Faculty of Veterinary Medicine, Freie Universität Berlin, Königsweg 65, 14163 Berlin, Germany
}

\begin{abstract}
The objective of this study was to assess the efficacy of ketoprofen compared with ceftiofur hydrochloride for the treatment of acute puerperal metritis (APM). Specifically, we set out to compare the incidence of extended treatment (extT) between treatment groups, to determine the prevalence of purulent vaginal discharge (PVD) and milk yield on the first 3 milk tests postpartum, and to analyze reproductive performance of cows treated with ketoprofen or ceftiofur. Cows with rectal temperature $\geq 39.5^{\circ} \mathrm{C}$ and reddish-brown fetid vaginal discharge within the first $10 \mathrm{~d}$ in milk (DIM) were diagnosed with APM. Day of enrollment and first day of treatment was considered study day 1. Rectal temperature was recorded daily until study day 7 . A total of 610 dairy cows with APM were enrolled in this randomized clinical trial. Cows meeting the inclusion criteria were allocated to treatment with ketoprofen (3 $\mathrm{mg} / \mathrm{kg}$ of body weight, $\mathrm{n}=300$ ) or treatment with ceftiofur ( $1 \mathrm{mg} / \mathrm{kg}$ of body weight, $\mathrm{n}=310)$ on study days 1,2 , and 3 . Cows that showed rectal temperature $\geq 39.5^{\circ} \mathrm{C}$ between study days 4 and 7 received an extT with ceftiofur for 3 (ketoprofen group) or 2 (ceftiofur group) more days. Cows were examined with the Metricheck device (Simcro, Hamilton, New Zealand) between DIM 21 and 40, and vaginal discharge was categorized on a 5-point scale according to the presence of pus. Cows with a score $\geq 2$ were classified as having PVD. Fifty-two cows ( 35 from ketoprofen group, 17 from ceftiofur group) were excluded from analysis due to missing protocol compliance $(\mathrm{n}=37)$ or concurrent disease $(\mathrm{n}$ $=15)$. Cows treated with ketoprofen were more likely to have an extT than cows treated with ceftiofur (61 vs. 31\%). Prevalence of PVD did not differ between the 2 treatment groups (ketoprofen, 56\%; ceftiofur, 53\%). Cows, however, that needed an extT after the initial
\end{abstract}

Received December 17, 2015.

Accepted May 17, 2016.

${ }^{1}$ Corresponding author: w.heuwieser@fu-berlin.de 3-d treatment were more likely to develop PVD than cows without extT (64 vs. 46\%). Treatment group did not affect milk yield (ketoprofen group, $35.5 \pm 0.4 \mathrm{~kg}$; ceftiofur group, $35.2 \pm 0.3 \mathrm{~kg}$ ), first artificial insemination pregnancy risk (ketoprofen group, $20 \%$ vs. ceftiofur group, 25\%), median days to first artificial insemination [ketoprofen group, 73 d, 95\% confidence interval (CI): $70-75$ d vs. ceftiofur group, 75 d, $95 \%$ CI: $72-76$ d] and median days to pregnancy (ketoprofen group, 144 d, $95 \%$ CI: $132-158$ d vs. ceftiofur group, 133 d, $95 \%$ CI: $119-153 \mathrm{~d})$. These results indicate that although cows initially treated with ketoprofen were more likely to receive extT, fewer doses of ceftiofur (1.83) were required compared with cows initially treated with ceftiofur (3.63). Moreover, the prevalence of PVD was not increased and milk yield and reproductive performance were not negatively affected by the initial treatment with ketoprofen.

Key words: acute puerperal metritis, animal health, antibiotic, nonsteroidal antiinflammatory drug (NSAID), reproduction

\section{INTRODUCTION}

Acute puerperal metritis (APM) is a common disease in early postpartum dairy cows (Chapinal et al., 2011; Sannmann et al., 2013b; Lima et al., 2014). Diagnosis of APM is based on reddish-brown fetid watery discharge and a rectal temperature $\geq 39.5^{\circ} \mathrm{C}$ within the first 21 DIM (Sheldon et al., 2006). Cows with APM have signs of systemic illness, are at greater risk of an impaired reproductive performance, are more likely to be culled, and have a greater risk of reduced milk production in comparison to healthy cows (Fourichon et al., 2000; Sheldon et al., 2006; Wittrock et al., 2011). Moreover, APM is a painful disease, and the pain response is particularly obvious during transrectal palpation of the uterus (Stojkov et al., 2015). In consequence, animal welfare as well as economic reasons illustrate the need of an effective treatment.

Different aerobic and anaerobic bacteria can be found in the infected uterus including Escherichia coli, 
Trueperella pyogenes, Prevotella spp., Fusobacterium necrophorum, Fusobacterium nucleatum, Mannheimia haemolytica, Staphylococcus spp., and Streptococcus spp. (Sheldon, 2004; Williams et al., 2005; Santos et al., 2011). Because of this wide range of pathogens, the suggestion to use antimicrobials with broad-spectrum activity as the preferred treatment is reasonable (Lima et al., 2014). Therefore, APM is commonly treated with third-generation cephalosporins (Machado et al., 2014). Another reason for the widespread use of ceftiofur administered parenterally is the 0-d withdrawal time for milk, resulting in a major financial incentive for using it (Grove-White and Murray, 2009; Scientific Advisory Group on Antimicrobials of the Committee for Medicinal Products for Veterinary Use, 2009; Lima et al., 2014). Moreover, the choice of other antimicrobials approved for the therapy of APM is limited. However, third-generation cephalosporins are very important antimicrobials for severe infections in humans, and their use in food-producing animals could potentially lead to an increased prevalence of resistance (Scientific Advisory Group on Antimicrobials of the Committee for Medicinal Products for Veterinary Use, 2009). Because antibiotic resistance is recognized as a top public health challenge facing the 21st century (Thomson et al., 2004), prudent use of antimicrobials and evaluation of alternative therapies are necessary.

In a clinical trial involving 1,023 cows, McLaughlin et al. (2012) showed self-cure of $55.3 \%$ in cows with APM not receiving antibiotic treatment compared with a cure of $74.3 \%$ of cows with APM treated with the longacting formulation of ceftiofur (ceftiofur crystalline free acid sterile suspension) twice. An unspecified number of cows with abnormal clinical signs (e.g., dehydration, anorexia, weakness, or severe depression) received supportive therapy. The results indicated that more than half the cows from the control group self-recovered. Moreover, Sannmann et al. (2013b) showed no negative effect on clinical cure, milk yield, serum haptoglobin concentration, and subsequent uterine health when cows with APM within the first 5 DIM were left untreated. However, animal welfare has to be considered in cows without any treatment with regard to visceral pain of the uterus and systemic signs of illness (Sheldon et al., 2006; Stojkov et al., 2015).

Nonsteroidal antiinflammatory drugs (NSAID) have been described as a supportive treatment of APM in addition to antibiotics (Amiridis et al., 2001; Drillich et al., 2007). These drugs have analgesic, antiinflammatory, antipyretic, and antiendotoxic effects and thus can increase animal health and well-being (Fitzpatrick et al., 2004; Laven et al., 2012). Ketoprofen, an NSAID with 0 -d withdrawal time in milk, was administered by Newby et al. (2013) after surgical correction of a left displaced abomasum to reduce pain, increase appetite, and increase milk production, and it has been approved for use in lactating cows in Europe. Antiinflammatory and analgesic effects of NSAID in combination with a remarkable self-cure of APM make it plausible to study the efficacy of ketoprofen in treatment of APM.

Therefore, the objective of this study was to evaluate if treating APM with ketoprofen is efficacious. Specifically, we set out to compare the incidence of extended treatment (extT) in cows with APM treated with ceftiofur or ketoprofen, to determine the prevalence of purulent vaginal discharge (PVD) between 21 and 40 DIM, the milk yield on the first 3 postpartum DHI tests, and to analyze reproductive performance (time to first AI, first AI pregnancy risk, and time to pregnancy) of cows treated with ketoprofen or ceftiofur.

\section{MATERIALS AND METHODS}

The experiment was conducted as a multisite completely randomized design. An a priori sample size calculation was conducted for the 2 main outcome variables: incidence of extT and first AI pregnancy risk.

For the comparison of the incidence of extT, Fisher's exact test for 2 independent groups was applied using $\mathrm{G}^{*}$ Power (version 3.1.5, University of Düsseldorf). We hypothesized that the incidence of extT would differ and that cows treated with ketoprofen would be more likely to need an extT than cows treated with ceftiofur. Our assumption for differences in incidence of extT was based on a previous study (McLaughlin et al., 2012), which described clinical cure of 74.3 and $55.3 \%$ for cows treated with ceftiofur and untreated control cows, respectively. Using $\alpha=0.05, \beta=0.05$, and a 2-tailed study design, a sample size of 155 cows per treatment group was necessary to verify our hypothesis.

We hypothesized that the treatment group would not affect first AI pregnancy risk. A first AI pregnancy risk of cows that previously suffered from metritis of $38 \%$ was assumed (Santos et al., 2010). Sample size calculation was based on a noninferiority study design, with a $10 \%$ maximum difference in first AI pregnancy risk between treatment groups required to declare noninferiority of a treatment with ketoprofen (Sealed Envelope Ltd., London, UK). A total of 292 cows per treatment group were estimated to be required to demonstrate noninferiority, assuming $\alpha=0.05$ and $\beta=0.20$.

\section{Farms and Cows}

The experiment was conducted on 6 commercial dairy farms in the northeastern part of Germany between June 2013 and February 2015. Participating farms were recruited based on convenience. Herd size ranged from 
732 to 2,244 with 677 to 1,319 milking cows. A total of 610 Holstein Friesian cows (188 primiparous and 422 multiparous) were enrolled. In 2 herds, only multiparous cows were enrolled owing to specific housing practices for primiparous cows. Cows were managed according to the guidelines set by the International Cooperation on Harmonisation of Technical Requirements for Registration of Veterinary Medical Products (Hellmann and Radeloff, 2000). The experimental procedures reported herein were conducted with the approval of the Institutional Animal Care and Use Committee of Freie Universität Berlin. Cows were housed indoors in freestall barns with different beddings (e.g., rubber mats, straw, or dried fermentation product from the on-site biogas plant) and were fed TMR. The TMR fed to prepartum and to early lactation cows were formulated to meet or exceed minimum nutritional requirements for highproducing dairy cows (NRC, 2001). Milk yield and milk quality was recorded and controlled at approximately monthly intervals by the local DHI association starting at 6 DIM. Reproductive performance and medical treatments were recorded and stored by the herd management software (Herde, version 5.81, dsp Agrosoft GmbH, Ketzin, Germany).

The yearly 21-d pregnancy rates were 16, 16, 12, 17, 17 , and $20 \%$ for farms $1,2,3,4,5$, and 6 , respectively. Voluntary waiting period was set at 40 DIM. Inseminations were performed following detection of estrus or timed artificial insemination (TAI). Inseminations based on TAI were conducted once per week. Ovulation was synchronized using GnRH (100 $\mu \mathrm{g}$ of gonadorelin, Gonavet Veyx, Veyx Pharma Ltd., Germany) and $\mathrm{PGF}_{2 \alpha}$ (500 $\mathrm{\mu g}$ of cloprostenol, PGF Veyx Forte, Veyx Pharma Ltd., Germany). For farms 1, 4, 5, and 6 , all cows not detected in estrus at $90 \pm 3$ DIM were enrolled into TAI and given GnRH. Seven days later cows received $\mathrm{PGF}_{2 \alpha}$ and $56 \mathrm{~h}$ later GnRH. Timed AI was performed $16 \mathrm{~h}$ after the second $\mathrm{GnRH}$ injection. Farm 2 used a Presynch-Ovsynch protocol for the first insemination. Cows were presynchronized with 2 injections of $\mathrm{PGF}_{2 \alpha}$ at $36 \pm 3$ and $50 \pm 3$ DIM. Cows detected in estrus after $\mathrm{PGF}_{2 \alpha}$ injection were inseminated. The remaining cows received their first $\mathrm{GnRH}$ injection with $64 \pm 3$ DIM. Seven days later, these cows received $\mathrm{PGF}_{2 \alpha}$ and $56 \mathrm{~h}$ later, GnRH. Timed AI was performed $16 \mathrm{~h}$ after the second $\mathrm{GnRH}$ injection at $74 \pm 3$ DIM. For farm 3, all cows not bred at $60 \pm 3$ DIM had their ovaries scanned using a transrectal ultrasound by the herd veterinarian. Cows with a corpus luteum $\geq 20 \mathrm{~mm}$ received $\mathrm{PGF}_{2 \alpha}, 56 \mathrm{~h}$ later $\mathrm{GnRH}$, and TAI $16 \mathrm{~h}$ later. Cows without a luteal structure or a corpus luteum $<20 \mathrm{~mm}$ received GnRH, 7 d later $\mathrm{PGF}_{2 \alpha}, 56 \mathrm{~h}$ later GnRH, and TAI 16 to $20 \mathrm{~h}$ later.

\section{Experimental Design}

Body temperature and vaginal discharge of all early lactation cows were evaluated by farm personnel using a standardized definition of APM within the first 10 DIM. Inclusion criteria were rectal temperature $\geq 39.5^{\circ} \mathrm{C}$ and a reddish-brown fetid watery vaginal discharge. Every person involved in the examination and treatment of cows was trained in advance to minimize deviations in diagnoses. Cows meeting inclusion criteria were assigned to treatment from a random list generated with Excel (Office 2010, Microsoft Deutschland GmbH, Munich, Germany) created in advance of the experiment for each farm separately. Cows were either treated with ketoprofen $(3 \mathrm{mg} / \mathrm{kg}$ of BW, Dinalgen, $150 \mathrm{mg} / \mathrm{mL}$, Bayer Vital GmbH, Leverkusen, Germany; Rifen, $100 \mathrm{mg} / \mathrm{mL}$, Vétoquinol $\mathrm{GmbH}$, Ravensburg, Germany; or Romefen, $100 \mathrm{mg} / \mathrm{mL}$, Merial GmbH, Hallbergmoos, Germany) or with ceftiofur $(1 \mathrm{mg} / \mathrm{kg}$ of BW, Excenel Flow, $50 \mathrm{mg} / \mathrm{mL}$, Zoetis Deutschland GmbH, Berlin, Germany, or Readycef $50 \mathrm{mg} / \mathrm{mL}$, Virbac Tierarzneimittel GmbH, Bad Oldesloe, Germany), both for 3 consecutive days. Ketoprofen has been approved in Germany for the treatment of fever, pain, and inflammation in dairy cows associated with respiratory tract infections, mastitis, lameness, arthritis, and traumatic injuries and for relief of pain to assist cows in standing after calving according to the specific product characteristics but not for APM. Therefore, the local veterinary authorities were notified about the experimental test.

Treatment group was not blinded to the attending person because duration of extT was different among treatment groups (Deluyker et al., 2005). Day of enrollment and first day of treatment was considered study day 1. Rectal temperature was recorded daily until study day 7 . Initial treatment was applied on study days 1,2 , and 3 . Cows with rectal temperature $\geq 39.5^{\circ} \mathrm{C}$ on day 4 received an extT with ceftiofur for $3 \mathrm{~d}$ (ketoprofen group) or 2 additional days (ceftiofur group). Cows showing fever on study days 5,6 , or 7 were examined for further systemic signs of illness (e.g., dullness, loss of appetite) and received extT based on the decision of the herd manager or veterinarian. Thus, extT could be initiated on study days $4,5,6$, or 7 . Clinical cure was defined as cows not receiving extT.

During the experiment each farm was visited biweekly by a veterinarian (A. Pohl) and the diagnosis of APM as well as protocol compliance were reviewed. Furthermore, cows between 21 and 40 DIM were examined for PVD as a sign for endometritis (Sheldon et al., 2006) with the Metricheck device (Simcro, Hamilton, New Zealand). Vaginal discharge was categorized on 
a 5 -point scale $(0=$ clear mucus; $1=$ mucus containing flecks of pus; $2=$ discharge containing less than $50 \%$ pus; discharge containing more than $50 \%$ pus; $4=$ reddish-brown fetid discharge) as previously described (Williams et al., 2005). A score of $\geq 2$ was considered abnormal and cows were classified as having PVD, formerly known as clinical endometritis (Sheldon et al., 2006; Lima et al., 2013).

The follow-up period was 200 DIM and data on AI, pregnancy, milk yield, and culling were generated from the herd's management software (Herde, version 5.81).

\section{Statistical Analysis}

Data were analyzed using SPSS for Windows (version 22, SPSS Inc., Munich, Germany) and Medcalc (version 15.0., Mariakerke, Belgium). The significance level was set at $P \leq 0.05$. Homogeneity of the proportion of parity (i.e., first, second, or greater lactation) and treatment group (i.e., ceftiofur and ketoprofen) was evaluated with the chi-squared test.

Generalized linear mixed models were fitted to the data to analyze the effect of treatment on the incidence of extT between study day 4 to 7, PVD between 21 and 40 DIM, and first AI pregnancy risk. All relevant factors were first tested in univariable models to identify the factors that should be included in the multivariable univariate final model. Farm was included as a random effect. Treatment group $(1=$ ceftiofur, $2=$ ketoprofen $)$ and parity $(1=$ primiparous, $2=$ multiparous $)$ were considered as factors of interest for all models. Calving season $(1=$ cold, $2=$ warm $)$ and extT $(1=$ no, $2=$ yes $)$ were furthermore included in the model with PVD and first AI pregnancy risk as outcome variables. Purulent vaginal discharge $(1=$ no, $2=$ yes $)$ was tested in the model of first AI pregnancy risk. Only variables with $P$ $<0.20$ were included in the final models. The model was built in a stepwise backward manner, and in the final model, variables with $P>0.05$ were excluded, whereas treatment group was forced to remain in the model regardless of level of significance. The total number of cases in the final model was restricted by the variable with the highest number of missing values. Odds ratios, confidence intervals, and $P$-values are reported. The confidence interval was set at $95 \%$.

A generalized linear mixed model ANOVA was used to analyze milk yield for the first 3 monthly DHI tests postpartum considering DHI test number as a repeated measure. The model was built according to the modelbuilding strategies provided by Dohoo et al. (2009). The effects of treatment group, extT, parity, calving season, PVD, DIM at DHI test, and their potential interactions with treatment group were tested accord- ingly. Cow and farm were included as a random effects. Treatment group was forced to remain in the model regardless of level of significance.

Intervals to first AI and to pregnancy were analyzed by survival analysis using the Cox's proportional hazard regression model. Right censoring occurred for cows that left the herd because of live culling, selling, ineligibility for breeding, or death. For analysis of time to pregnancy, cows not pregnant after 200 DIM were censored. The model for time to first AI as well as time to pregnancy included treatment group, extT, parity, farm, calving season, and PVD as categorical variables. The model was built in a stepwise backward manner by removing all variables with $P>0.05$ from the model. Regardless of the significance level, farm and treatment were forced to remain in the model. For descriptive statistics, univariable results from Kaplan-Meier survival analysis were used.

To determine the effect of treatment on the mean number of medical applications and on the mean number of antimicrobial doses, a generalized linear model was conducted using Poisson regression for data following Poisson distribution.

\section{RESULTS}

The overall incidence of metritis was $16.6 \%$, ranging between 7.2 and $38.1 \%$ depending on farm (Table 1). A total of 610 cows (300 initially treated with ketoprofen and 310 treated with ceftiofur) were enrolled in this experiment. The distribution of parity was balanced among treatment groups (29\% primiparous cows in ceftiofur group and $32 \%$ primiparous cows in ketoprofen group; $P=0.26$ ). Fifty-two cows (35 from ketoprofen group, 17 from ceftiofur group) were excluded from analysis due to missing protocol compliance (n $=37)$ or concurrent disease $(\mathrm{n}=15)$. Unadjusted results of descriptive statistics accounting for the effect of treatment group on the incidence of extT between study days 4 to 7 , PVD, milk yield, and reproductive performance are given in Table 2 .

A total of 558 cows were analyzed for the incidence of extT. Cows treated with ketoprofen had $3.43(95 \%$ CI: 2.40-4.88; $P<0.001$; Table 3) times the odds of extT compared with cows initially treated with ceftiofur. Furthermore, multiparous cows had 0.60 (95\% CI: $0.39-0.91 ; P=0.017)$ times the odds of extT compared with primiparous cows.

A total of 438 cows were examined for PVD. Cows without examination either left the herd before examination date (14 from ketoprofen group and 16 from ceftiofur group) or were not cooperative or not found during farm visit. Treatment group was not associated 
Table 1. Summary of enrollment of cows with acute puerperal metritis (APM) meeting the inclusion criteria (i.e., rectal temperature $\geq 39.5^{\circ} \mathrm{C}$ and fetid reddish-brown vaginal discharge within the first $10 \mathrm{DIM}$ ) on the 6 participating farms

\begin{tabular}{|c|c|c|c|c|}
\hline \multirow[b]{2}{*}{ Enrollment } & \multicolumn{2}{|c|}{$\begin{array}{l}\text { No. of cows with APM initially } \\
\text { treated with } 3 \text { daily doses of }\end{array}$} & \multirow[b]{2}{*}{ Total } & \multirow[b]{2}{*}{$\begin{array}{c}\text { Metritis } \\
\text { incidence }(\%\end{array}$} \\
\hline & $\begin{array}{l}3 \mathrm{mg} / \mathrm{kg} \\
\text { ketoprofen }\end{array}$ & $\begin{array}{l}1 \mathrm{mg} / \mathrm{kg} \\
\text { ceftiofur }\end{array}$ & & \\
\hline Farm 1 & 26 & 30 & 56 & 15.6 \\
\hline Farm 2 & 60 & 59 & 119 & 19.4 \\
\hline Farm 3 & 96 & 96 & 192 & 38.1 \\
\hline Farm 4 & 44 & 44 & 88 & 7.2 \\
\hline Farm 5 & 36 & 37 & 73 & 33.3 \\
\hline Farm 6 & 38 & 44 & 82 & 10.8 \\
\hline Total & 300 & 310 & 610 & 16.6 \\
\hline
\end{tabular}

with the prevalence of PVD $(P=0.614$; Table 4$)$. However, cows with extT had 2.13 (95\% CI: $1.40-3.25 ; P$ $<0.001)$ times the odds of PVD compared with cows without extT. Moreover, cows that calved in the warm season had 1.66 (95\% CI: $1.03-2.66 ; P=0.036)$ times the odds of PVD compared with cows that calved in the cold season.

A total of 480 cows were analyzed for first AI pregnancy risk and only cows with at least one AI within the observational period of 200 DIM were included. Cows that left the herd before first AI or that were not eligible to be bred were excluded from analysis (37 from ketoprofen group and 41 from ceftiofur group). Treatment group did not affect first AI pregnancy risk $(P=0.695)$. Parity, however, was associated with first AI pregnancy risk and multiparous cows had 0.54 (95\% CI: $0.32-0.91 ; P=0.02)$ times the odds of pregnancy at first AI compared with primiparous cows.

A total of 1,443 DHI test data were included in the final model for milk yield. Treatment group did not affect milk yield for the first 3 DHI tests $(P=0.582)$. Estimated marginal means $\pm \mathrm{SE}$ of cows treated with ketoprofen were $34.6 \pm 5.9 \mathrm{~kg}$ (95\% CI: 22.6-46.1 kg) and $34.4 \pm 5.9 \mathrm{~kg}(95 \% \mathrm{CI}: 22.9-46.3 \mathrm{~kg})$ for cows treated with ceftiofur. Multiparous cows had a greater milk production than primiparous cows $(P<0.001)$. Estimated marginal means of multiparous cows were $38.1 \pm 5.9 \mathrm{~kg}(95 \%$ CI: $19.1-42.6 \mathrm{~kg})$ and $30.9 \pm 5.9 \mathrm{~kg}$ (95\% CI: $19.1-42.6 \mathrm{~kg}$ ) for primiparous cows. Furthermore, cows that calved in the cold season had greater milk production $(35.0 \pm 5.9 \mathrm{~kg}, 95 \%$ CI: $23.2-46.7 \mathrm{~kg})$ than cows that calved in the warm season $(34.0 \pm 5.9$ kg, 95\% CI: $22.2-45.7 \mathrm{~kg} ; P=0.025)$. Moreover, DIM at DHI test affected milk yield for the first 3 DHI tests $(P<0.001)$.

A total of 438 cows were analyzed for time to first AI within 200 DIM. Treatment did not affect the time until cows had their first AI $(P=0.41$; Figure 1$)$. The hazard ratio for first AI within 200 DIM was $0.73(95 \%$ CI: $0.57-0.94 ; P=0.016)$ for multiparous cows and

Table 2. Unadjusted descriptive statistics of the effect of treatment group on the incidence of extended treatment, purulent vaginal discharge, milk yield, and reproductive performance of cows with acute puerperal metritis (APM)

\begin{tabular}{lcc}
\hline & \multicolumn{2}{c}{$\begin{array}{c}\text { Cows with APM treated } \\
\text { with } 3 \text { daily doses of }\end{array}$} \\
\cline { 2 - 3 } Variable & $3 \mathrm{mg} / \mathrm{kg}$ ketoprofen & $1 \mathrm{mg} / \mathrm{kg}$ ceftiofur \\
\hline Extended treatment $\left.{ }^{1}[\% \text { (no./no. })^{2}\right]$ & $61(162 / 265)$ & $31(92 / 293)$ \\
Purulent vaginal discharge [\% (no./no.)] & $56(116 / 209)$ & $53(122 / 229)$ \\
First AI pregnancy risk [\% (no./no.)] & $20(46 / 228)$ & $25(62 / 252)$ \\
Mean milk yield $\pm \mathrm{SE}$ & $35.5 \pm 0.4$ & $35.2 \pm 0.3$ \\
& $(\mathrm{n}=256)$ & $(\mathrm{n}=284)$ \\
Median days to first AI by $200 \mathrm{DIM}^{3}$ & $73(70-75)$ & $75(72-76)$ \\
& $(\mathrm{n}=265)$ & $(\mathrm{n}=293)$ \\
Median days to pregnancy by $200 \mathrm{DIM}^{3}$ & $144(132-158)$ & $133(119-153)$ \\
& $(\mathrm{n}=265)$ & $(\mathrm{n}=293)$ \\
\hline
\end{tabular}

${ }^{1}$ Rectal temperature $>39.5^{\circ} \mathrm{C}$ between study days 4 and $7: 3 \mathrm{~d}$ (cows initially treated with ketoprofen) or $2 \mathrm{~d}$ (cows initially treated with ceftiofur) of treatment with ceftiofur.

${ }^{2}$ Number divided by total number.

${ }^{3}$ Univariable results from Kaplan-Meier survival analysis; $95 \%$ CI in parentheses. 
Table 3. Final mixed model logistic regression of 558 Holstein cows with acute puerperal metritis enrolled in a clinical trial investigating the effect of treatment on study days 1 to 3 and parity on the subsequent incidence of extended treatment between study days 4 to 7 accounting for the random effect of farm

\begin{tabular}{lccc}
\hline Variable & $\begin{array}{c}\text { Odds } \\
\text { ratio }\end{array}$ & $95 \% \mathrm{CI}$ & $P$-value \\
\hline $\begin{array}{l}\text { Treatment } \\
\text { Ceftiofur }\end{array}$ & Referent & & $<0.001$ \\
$\begin{array}{l}\text { Ketoprofen } \\
\text { Parity }\end{array}$ & 3.43 & $2.40-4.88$ & \\
$\begin{array}{l}\text { Primiparous } \\
\text { Multiparous }\end{array}$ & $\begin{array}{c}\text { Referent } \\
0.60\end{array}$ & $0.39-0.91$ & \\
\hline
\end{tabular}

${ }^{1}$ Initial treatment with ceftiofur or ketoprofen on 3 consecutive days in cows meeting inclusion criteria (rectal temperature $\geq 39.5^{\circ} \mathrm{C}$ and fetid watery vaginal discharge within the first 10 DIM).

0.63 (95\% CI: $0.51-0.78 ; P<0.001)$ for cows with PVD compared with primiparous cows and cows without PVD. Furthermore, an overall effect of farm was present $(P=0.007)$.

A total of 438 cows were analyzed for time to pregnancy within 200 DIM. Treatment did not affect the time the cows conceived $(P=0.97$; Figure 1$)$. The hazard ratio for pregnancy within 200 DIM was 0.71 (95\% CI: $0.53-0.95 ; P=0.023)$ for multiparous cows and 0.69 (95\% CI: $0.53-0.95 ; P=0.002)$ for cows with PVD compared with primiparous cows and cows without PVD, respectively. Additionally, an overall effect of farm was present $(P=0.001)$.

Cows initially treated with ketoprofen had $4.83 \pm$ 1.47 medical applications (3 doses initial treatment with ketoprofen and, if necessary, 3 doses extT with ceftiofur), and cows initially treated with ceftiofur had

Table 4. Final mixed model logistic regression model of 438 Holstein cows with acute puerperal metritis enrolled in a clinical trial investigating the effect of treatment on study days 1 to 3 , incidence of extended treatment between study days 4 to 7 , and season on the prevalence of purulent vaginal discharge between DIM 21 and 40 accounting for the random effect of farm

\begin{tabular}{|c|c|c|c|}
\hline Variable & $\begin{array}{l}\text { Odds } \\
\text { ratio }\end{array}$ & $95 \% \mathrm{CI}$ & $P$-value \\
\hline \multicolumn{4}{|l|}{ Treatment $^{1}$} \\
\hline Ceftiofur & Referent & & 0.614 \\
\hline Ketoprofen & 0.90 & $0.59-1.36$ & \\
\hline \multicolumn{4}{|c|}{ Extended treatment ${ }^{2}$} \\
\hline No & Referent & & $<0.001$ \\
\hline Yes & 2.13 & $1.40-3.25$ & \\
\hline \multicolumn{4}{|l|}{ Season } \\
\hline Cold & Referent & & 0.036 \\
\hline Warm & 1.66 & $1.03-2.66$ & \\
\hline
\end{tabular}

${ }^{1}$ Initial treatment with ketoprofen or ceftiofur on 3 consecutive days in cows meeting inclusion criteria (rectal temperature $\geq 39.5^{\circ} \mathrm{C}$ and fetid, watery vaginal discharge within the first 10 DIM).

${ }^{2}$ Rectal temperature $\geq 39.5^{\circ} \mathrm{C}$ between study days 4 and $7: 3 \mathrm{~d}$ (cows initially treated with ketoprofen) or $2 \mathrm{~d}$ (cows initially treated with ceftiofur) of treatment with ceftiofur.
$3.63 \pm 0.93$ medical applications ( 3 doses initial treatment with ceftiofur and, if necessary, 2 doses extT with ceftiofur; $P<0.001)$. Moreover, cows initially treated with ketoprofen had $1.83 \pm 1.47$ antimicrobial doses (if necessary, 3 doses extT with ceftiofur), and cows treated with ceftiofur had $3.63 \pm 0.93$ antimicrobial doses (3 doses initial treatment with ceftiofur and, if necessary, 2 doses extT with ceftiofur; $P<0.001$ ).

\section{DISCUSSION}

Postpartum uterine diseases are common and of great importance in dairy cows as shown by an incidence of
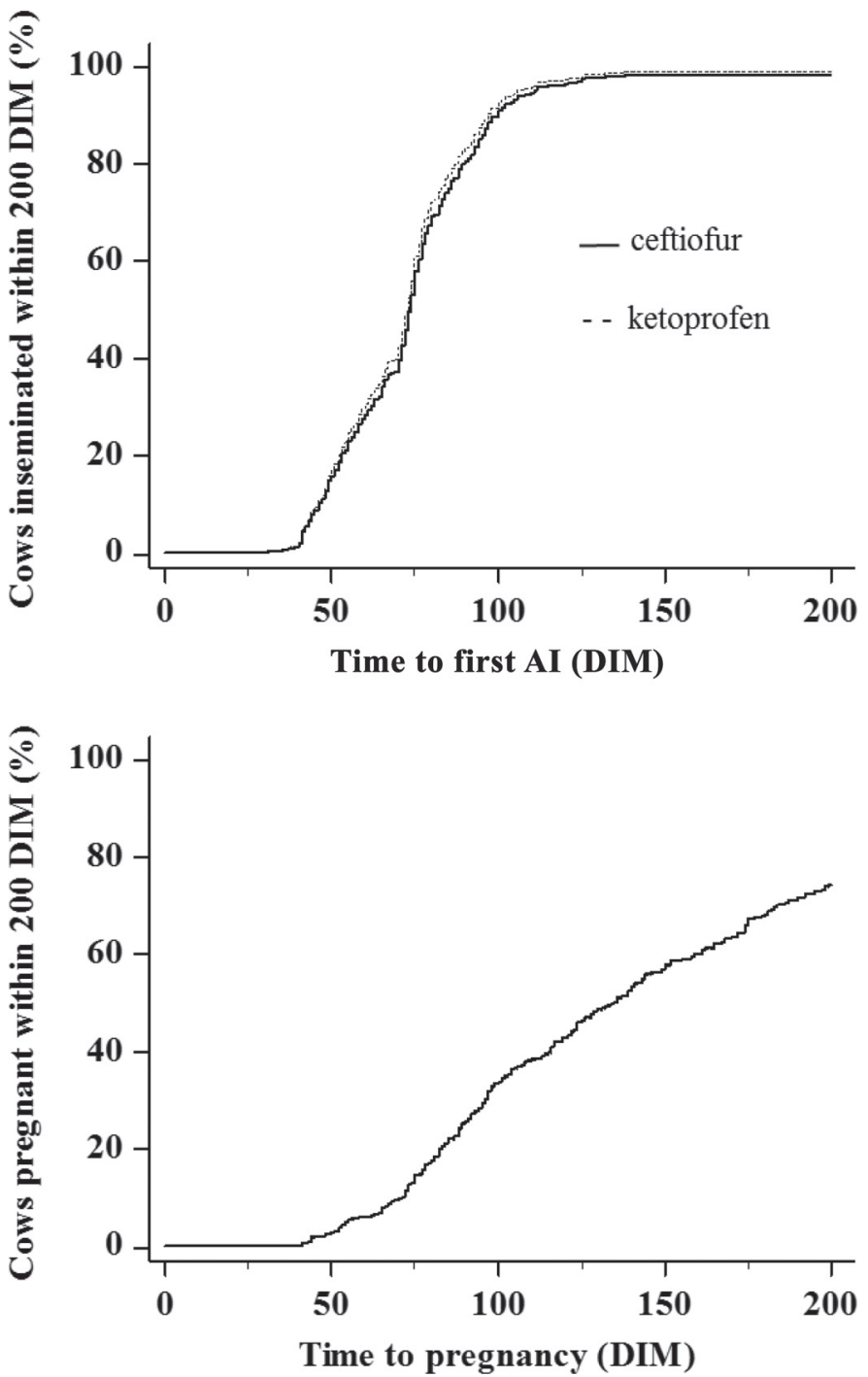

Figure 1. Cox proportional survival analysis illustrating the effect of treatment on time to first AI and time to pregnancy. Treatment did not affect days to first insemination (hazard ratio $=1.09 ; 95 \% \mathrm{CI}$; $0.89-1.32, P=0.41$ ) or days to pregnancy (hazard ratio $=1.00 ; 95 \%$ CI: $0.79-1.26, P=0.97$; curves of treatments overlap). 
APM between 14.8 and 40.9\% (Chapinal et al., 2011; Sannmann et al., 2013b; Lima et al., 2014). This wide range is also reflected by our results, which showed incidences of APM between 7.2 and $38.1 \%$ depending on the farm.

Cows initially treated with ketoprofen were more likely to receive extT than cows initially treated with ceftiofur. The quality of discharge was not regarded as a criterion for extT at this point, because about $50 \%$ of cows with APM still have discharge even at day 6 after first treatment (Drillich et al., 2001). To our knowledge, evidence-based information is not available for cows with APM treated with NSAID alone in respect to clinical cure, reproductive performance, or milk yield. Amiridis et al. (2001), however, showed that cows treated with NSAID in combination with antibiotic treatment had reduced pyrexia, faster clinical improvement, a more rapid uterine involution, and an earlier estrus compared with cows only treated antibiotically, illustrating a beneficial effect of NSAID. Chenault et al. (2004) and McLaughlin et al. (2012) found greater clinical cure (15-19 percentage points) for cows treated with ceftiofur compared with untreated control cows. Because of several concerns such as animal welfare, painful disease, and economic losses (Drillich et al., 2001; Lima et al., 2014; Stojkov et al., 2015), we did not include an untreated control group in our experiment. Therefore, we cannot determine whether the cows initially treated with ketoprofen that did not need extT self-cured or recovered due to the antiinflammatory, antipyretic, and analgesic effects of the NSAID. Moreover, even though the definition of APM has been widely accepted in research and used in practice (Mc Laughlin et al., 2012; Lima et al., 2014; Machado et al., 2014), it is suboptimal, and both type I and type II errors can occur (Sannmann and Heuwieser, 2015). The interobserver agreement of olfactory assessment of vaginal discharge is only moderate (Sannmann et al., 2013a), and body temperature is influenced by several factors such as climate, time of day, and insertion depth of the thermometer (Burfeind et al., 2010, 2012). Although any experiment has limitations and the incidence of extT differed among farms, the investigators trained all personnel involved in diagnosis of APM and reviewed the diagnostic criteria biweekly during farm visits to minimize variations in diagnosis between farms.

Although cows initially treated with ketoprofen had a larger mean number of medical applications (4.83) compared with cows initially treated with ceftiofur (3.63), considerably fewer doses of ceftiofur were applied (1.83 vs. 3.63). Consequently, a remarkable potential exists for reducing antimicrobial treatment by implementing this treatment protocol. Discussion is needed for whether greater odds of ext T are justified by a lower usage of antibiotics. We are aware that this discussion is not trivial and requires further scientific and ethical attention.

The treatment of APM with ceftiofur as a new generation cephalosporin, however, is a critical issue with regard to antibiotic resistance because the prudent use of critically important antimicrobials is mandatory (Pyörälä et al., 2014) and a withdrawal from the market has even been considered (Grove-White and Murray, 2009). Moreover, NSAID are known to likely be of value in diseases in which inflammation, endotoxemia, and pain are major components (Fitzpatrick et al., 2004; Laven et al., 2012; Stojkov et al., 2015). Furthermore, several studies evaluated the effect of treatment with NSAID on pain reaction in cows with mastitis, lame cows, and calves after dehorning (Chapinal et al., 2010; Heinrich et al., 2010; Fitzpatrick at al., 2013). Fitzpatrick et al. (2013) found that udder pain sensitivity did not increase in meloxicam-treated animals after mastitis induction. In contrast, untreated control cows showed a higher udder pain sensitivity measured by a pressure algometer after mastitis induction. However, no experiment has evaluated the effect on pain sensitivity in cows with APM treated with NSAID, and treatment with NSAID can only be speculated to reduce pain in cows with APM. Accordingly, further research is needed to evaluate if NSAID are efficacious to reduce pain in cows with APM.

The applied dosage of ceftiofur was $1 \mathrm{mg} / \mathrm{kg}$ in this experiment. Chenault et al. (2004) found that cows treated with $2.2 \mathrm{mg} / \mathrm{kg}$ had higher cure rates $(77 \%)$ on d 14 than after treatment with $1.1 \mathrm{mg}$ of ceftiofur hydrochloride per $\mathrm{kg}$ of BW (65\%) or control cows $(62 \%)$. However, ceftiofur in Europe is labeled for a dosage of $1 \mathrm{mg} / \mathrm{kg}$ of BW, and several studies have demonstrated efficacy with this dosage. Moreover, Drillich et al. (2006) determined concentrations of ceftiofur derivatives in serum, endometrium, caruncles, cotyledons, and lochia of cows having retained fetal membranes during $72 \mathrm{~h}$ after treatment with ceftiofur $(1 \mathrm{mg} / \mathrm{kg})$. The results showed that mean concentration of ceftiofur derivatives exceeded the reported minimum drug concentrations required to inhibit the growth of $90 \%$ of isolates for relevant bacteria such as E. coli, F. necrophorum, and T. pyogenes.

Treatment group did not affect the prevalence of PVD. However, cows that needed extT were more likely to develop PVD than cows that did not need extT. The immune system of the cows without extT in combination with the medication applied may have cured APM more effectively within $3 \mathrm{~d}$ of treatment, and therefore, a carryover effect in form of PVD could not be seen. On the other hand, it is possible that cows without extT 
were only mildly metritic or even had a false-positive diagnosis because of the potential confounders of diagnosis mentioned previously.

Treatment group did not affect milk yield or reproductive performance, indicating that an initial treatment with ketoprofen had no negative effects on subsequent performance. Other factors (i.e., parity, farm, season, and PVD) were associated with milk yield or fertility. Differences in breeding strategies on different farms might have influenced time to first AI as well as time to pregnancy, because time to first AI was predetermined in cows with synchronization protocol followed by TAI.

Regarding first AI pregnancy risk, however, differences in breeding programs were less important because time of the first AI was not considered in this outcome. Furthermore, randomization ensured that cows in different treatment groups were handled equally at each farm. Moreover, Rabiee et al. (2005) showed that pregnancy rate did not differ between cows receiving TAI and those inseminated following detected estrus.

\section{CONCLUSIONS}

Cows with APM that were initially treated with ketoprofen had greater odds of extT than cows initially treated with ceftiofur. However, they required fewer doses of antibiotics overall, without negative effects on the prevalence of PVD, milk yield, or reproductive performance. Consequently, considerable potential exists for reducing antimicrobial treatment by implementing a treatment protocol starting with ketoprofen; however, more doses of medical applications have to be expected.

\section{ACKNOWLEDGMENTS}

We gratefully acknowledge the farm personnel of the dairy farms for their kind cooperation. Furthermore, we thank the staff of the Clinic of Reproduction, Freie Universität Berlin, Germany, for their support during the practical part of the experiment. The assistance of Maria Grau and Tanita Drenikow (Clinic of Reproduction) during the course of this experiment is greatly appreciated. Alina Pohl was partially funded by Tiergyn e.V. (Berlin, Germany).

\section{REFERENCES}

Amiridis, G. S., L. Leontides, E. Tassos, P. Kostoulas, and G. C. Fthenakis. 2001. Flunixin meglumine accelerates uterine involution and shortens the calving-to-first-oestrus interval in cows with puerperal metritis. J. Vet. Pharmacol. Ther. 24:365-367.

Burfeind, O., V. S. Suthar, and W. Heuwieser. 2012. Effect of heat stress on body temperature in healthy early postpartum dairy cows. Theriogenology 78:2031-2038.
Burfeind, O., M. A. G. von Keyserlingk, D. M. Weary, D. M. Veira, and W. Heuwieser. 2010. Short communication: Repeatability of measures of rectal temperature in dairy cows. J. Dairy Sci. 93:624-627.

Chapinal, N., M. Carson, T. F. Duffield, M. Capel, S. Godden, M. Overton, J. E. P. Santos, and S. J. LeBlanc. 2011. The association of serum metabolites with clinical disease during the transition period. J. Dairy Sci. 94:4897-4903.

Chapinal, N., A. M. de Passillé, J. Rushen, and S. Wagner. 2010. Automated methods for detecting lameness and measuring analgesia in dairy cattle. J. Dairy Sci. 93:2007-2013.

Chenault, J. R., J. F. McAllister, S. T. Chester, K. J. Dame, F. M. Kausche, and E. J. Robb. 2004. Efficacy of ceftiofur hydrochloride sterile suspension administered parenterally for the treatment of acute postpartum metritis in dairy cows. J. Am. Vet. Med. Assoc. 224:1634-1639.

Deluyker, H. A., S. N. Van Oye, and J. F. Boucher. 2005. Factors affecting cure and somatic cell count after pirlimycin treatment of subclinical mastitis in lactating cows. J. Dairy Sci. 88:604-614.

Dohoo, I. R., S. W. Martin, and H. Stryhn. 2009. Veterinary Epidemiologic Research. 2nd ed. University of Prince Edward Island, Charlottetown, PEI, Canada.

Drillich, M., O. Beetz, A. Pfützner, M. Sabin, H. J. Sabin, P. Kutzer, H. Nattermann, and W. Heuwieser. 2001. Evaluation of a systemic antibiotic treatment of toxic puerperal metritis in dairy cows. J. Dairy Sci. 84:2010-2017.

Drillich, M., M. Mahlstedt, U. Reichert, B. A. Tenhagen, and W. Heuwieser. 2006. Strategies to improve the therapy of retained fetal membranes in dairy cows. J. Dairy Sci. 89:627-635.

Drillich, M., D. Voigt, D. Forderung, and W. Heuwieser. 2007. Treatment of acute puerperal metritis with flunixin meglumine in addition to antibiotic treatment. J. Dairy Sci. 90:3758-3763.

Fitzpatrick, C. E., N. Chapinal, C. S. Petersson-Wolfe, T. J. DeVries, D. F. Kelton, T. F. Duffield, and K. E. Leslie. 2013. The effect of meloxicam on pain sensitivity, rumination time, and clinical signs in dairy cows with endotoxin-induced clinical mastitis. J. Dairy Sci. 96:2847-2856.

Fitzpatrick, J. L., A. M. Nolan, P. Lees, and S. A. May. 2004. Inflammation and pain. Pages 1045-1066 in Bovine Medicine. 2nd ed. Blackwell Publishing, Oxford, UK.

Fourichon, C., H. Seegers, and X. Malher. 2000. Effect of disease on reproduction in the dairy cow: A meta-analysis. Theriogenology 53:1729-1759.

Grove-White, D., and R. Murray. 2009. Use of antimicrobials. Vet. Rec. 164:727.

Heinrich, A., T. F. Duffield, K. D. Lissemore, and S. T. Millman. 2010. The effect of meloxicam on behavior and pain sensitivity of dairy calves following cautery dehorning with a local anesthetic. J. Dairy Sci. 93:2450-2457.

Hellmann, K., and I. Radeloff. 2000. International Cooperation on Harmonisation of Technical Requirements of Veterinary Medicinal Products (VICH). VICH, Brussels, Belgium.

Laven, R., P. Chambers, and K. Stafford. 2012. Using non-steroidal anti-inflammatory drugs around calving: Maximizing comfort, productivity and fertility. Vet. J. 192:8-12.

Lima, F. S., R. S. Bisinotto, E. S. Ribeiro, L. F. Greco, H. Ayres, M. G. Favoreto, M. R. Carvalho, K. N. Galvao, and J. E. Santos. 2013. Effects of 1 or 2 treatments with prostaglandin $\mathrm{F}_{2 \alpha}$ on subclinical endometritis and fertility in lactating dairy cows inseminated by timed artificial insemination. J. Dairy Sci. 96:6480-6488.

Lima, F. S., A. Vieira-Neto, G. S. Vasconcellos, R. D. Mingoti, E. Karakaya, E. Sole, R. S. Bisinotto, N. Martinez, C. A. Risco, K. N. Galvao, and J. E. Santos. 2014. Efficacy of ampicillin trihydrate or ceftiofur hydrochloride for treatment of metritis and subsequent fertility in dairy cows. J. Dairy Sci. 97:5401-5414.

Machado, V. S., M. L. de Souza Bicalho, E. B. S. M. Junior, R. Rossi B. L. Ribeiro, S. Lima, T. Santos, A. Kussler, C. Foditsch, and E. K. Ganda. 2014. Subcutaneous immunization with inactivated bacterial components and purified protein of Escherichia coli, Fusobacterium necrophorum and Trueperella pyogenes prevents puerperal metritis in Holstein dairy cows. PLoS One 9:e91734. 
McLaughlin, C. L., E. Stanisiewski, M. J. Lucas, C. P. Cornell, J. Watkins, L. Bryson, J. K. S. Tena, J. Hallberg, and J. R. Chenault. 2012. Evaluation of two doses of ceftiofur crystalline free acid sterile suspension for treatment of metritis in lactating dairy cows. J. Dairy Sci. 95:4363-4371.

NRC. 2001. Nutrient Requirements of Dairy Cattle. 7th rev. ed. National Academies Press, Washington, DC.

Newby, N. C., D. L. Pearl, S. J. LeBlanc, K. E. Leslie, M. A. G. von Keyserlingk, and T. F. Duffield. 2013. The effect of administering ketoprofen on the physiology and behavior of dairy cows following surgery to correct a left displaced abomasum. J. Dairy Sci. 96:1511-1520.

Pyörälä, S., J. Taponen, and T. Katila. 2014. Use of antimicrobials in the treatment of reproductive diseases in cattle and horses. Reprod. Domest. Anim. 49(Suppl. 3):16-26.

Rabiee, A. R., I. J. Lean, and M. A. Stevenson. 2005. Efficacy of Ovsynch program on reproductive performance in dairy cattle: A meta-analysis. J. Dairy Sci. 88:2754-2770.

Sannmann, I., O. Burfeind, V. Suthar, A. Bos, M. Bruins, and W. Heuwieser. 2013a. Technical note: Evaluation of odor from vaginal discharge of cows in the first 10 days after calving by olfactory cognition and an electronic device. J. Dairy Sci. 96:5773-5779.

Sannmann, I., O. Burfeind, R. Voigtsberger, and W. Heuwieser. 2013b. Comparison of two monitoring and treatment strategies for cows with acute puerperal metritis. Theriogenology 79:961-969.

Sannmann, I., and W. Heuwieser. 2015. Technical note: Intraobserver, interobserver, and test-retest reliabilities of an assessment of vaginal discharge from cows with and without acute puerperal metritis. J. Dairy Sci. 98:5460-5466.

Santos, J. E., R. S. Bisinotto, E. S. Ribeiro, F. S. Lima, L. F. Greco, C. R. Staples, and W. W. Thatcher. 2010. Applying nutrition and physiology to improve reproduction in dairy cattle. Soc. Reprod. Fertil. Suppl. 67:387-403.

Santos, T. M. A., R. O. Gilbert, and R. C. Bicalho. 2011. Metagenomic analysis of the uterine bacterial microbiota in healthy and metritic postpartum dairy cows. J. Dairy Sci. 94:291-302.

Scientific Advisory Group on Antimicrobials of the Committee for Medicinal Products for Veterinary Use. 2009. Reflection paper on the use of third and fourth generation cephalosporins in food producing animals in the European Union: Development of resistance and impact on human and animal health. J. Vet. Pharmacol. Ther. $32: 515-533$.

Sheldon, I. M. 2004. The postpartum uterus. Vet. Clin. North Am. Food Anim. Pract. 20:569-591.

Sheldon, I. M., G. S. Lewis, S. LeBlanc, and R. O. Gilbert. 2006. Defining postpartum uterine disease in cattle. Theriogenology 65:1516-1530

Stojkov, J., M. A. G. von Keyserlingk, J. N. Marchant-Forde, and D. M. Weary. 2015. Assessment of visceral pain associated with metritis in dairy cows. J. Dairy Sci. 98:5352-5361.

Thomson, C. J., E. Power, H. Ruebsamen-Waigmann, and H. Labischinski. 2004. Antibacterial research and development in the 21st century-An industry perspective of the challenges. Curr. Opin. Microbiol. 7:445-450.

Williams, E. J., D. P. Fischer, D. U. Pfeiffer, G. C. W. England, D. E. Noakes, H. Dobson, and I. M. Sheldon. 2005. Clinical evaluation of postpartum vaginal mucus reflects uterine bacterial infection and the immune response in cattle. Theriogenology 63:102-117.

Wittrock, J. M., K. L. Proudfoot, D. M. Weary, and M. A. G. von Keyserlingk. 2011. Short communication: Metritis affects milk production and cull rate of Holstein multiparous and primiparous dairy cows differently. J. Dairy Sci. 94:2408-2412. 